\title{
DIREITO E A HIPÓTESE DA AUTOPOIESE TECNOLÓGICA: UM DIÁLOGO COM LUHMANN E A PINTURA DE RICHARD LINDNER
}

Rafael Simioni*

\begin{tabular}{l|l}
\hline RECEBIDO EM: & 16.11 .2021 \\
\hline APROVADO EM: & 6.12 .2021 \\
\hline
\end{tabular}

* Graduado em Direito pela Universidade de Caxias do Sul (UCS), mestre em Direito pela UCS, doutor em Direito Público pela Universidade do Vale do Rio dos Sinos (Unisinos) e pós-doutor em Filosofia e Teoria do Direito pela Universidade de Coimbra (UC). Professor permanente do Programa de Pós-Graduação em Direito (PPGD) da Faculdade de Direito do Sul de Minas (FDSM) e do Programa de Pós-Graduação (Mestrado e Doutorado) em Educação, Conhecimento e Sociedade da Universidade do Vale do Sapucaí (Univás). Coordenador do Programa de Pós-Graduação em Direito da FDSM. Pesquisador-líder do Grupo de Pesquisa Margens do Direito (PPGD/FDSM) e Arte e Direito (PPGD/FDSM). E-mail: simioni2010@gmail.com 
- RAFAEL SIMIONI

- FIGURA 1 • RICHARD LINDNER, TELEPHONE (1966)

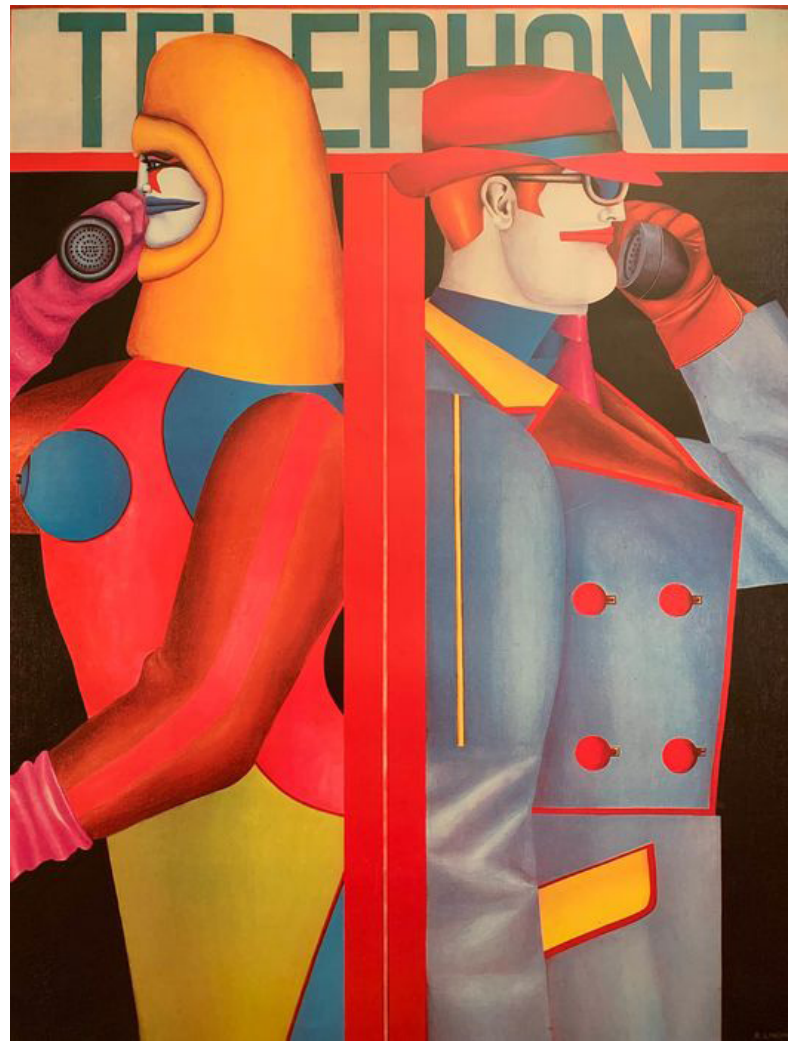

FONTE: REPRODUÇÃO COM AUTORIZAÇĀO DE ANOUK PAPADIAMANDIS, TITULAR DOS DIREITOS DE IMAGEM.

- RESUmo: Este artigo discute, sob uma perspectiva jurídica, a noção de técnica/tecnologia na teoria dos sistemas sociais autopoiéticos de Niklas Luhmann. Para tanto, estabelece um diálogo com três pinturas de Richard Lindner, de modo a problematizar a observação luhmanniana da tecnologia e a hipótese da autopoiese tecnológica desenvolvida por pensadores contemporâneos, como Reichel e Rafael. Trata-se de uma pesquisa de revisão literária e com a análise das imagens baseadas em uma dialética entre a organização pictórica do mechanical cubism de Lindner e as problematizações luhmannianas sobre a tecnologia. Como resultado, observa-se que não há elementos capazes de marcar a hipótese de uma genuína autopoiese tecnológica, mas não há nada que sinalize a sua impossibilidade, em uma sociedade na qual cada vez mais o caos da simultaneidade se torna um problema de seletividade permanente.

- Palavras-chave: Autopoiese; direito; tecnologia. 


\section{LAW AND THE HYPOTHESIS OF TECHNOLOGICAL}

AUTOPOIESIS: A DIALOGUE WITH LUHMANN AND THE RICHARD LINDNER'S PAINTING

- abstRAct: This paper discusses, from a legal perspective, the notion of technique/ technology in Niklas Luhmann's theory of autopoietic social systems. Therefore, it establishes a dialogue with three paintings by Richard Lindner, in order to problematize the Luhmannian observation of technology and the hypothesis of technological autopoiesis developed by contemporary thinkers such as Reichel and Rafael. This is a literary review research with image analysis based on a dialectic between the pictorial organization of Lindner's mechanical cubism and Luhmann's problematizations about technology. As a result, it is observed that there are no elements capable of marking the hypothesis of a genuine technological autopoiesis, but there is nothing that signals its impossibility, in a society in which the chaos of simultaneity increasingly becomes a problem of permanent selectivity.

\section{Introdução}

As pinturas de Richard Lindner ${ }^{1}$ são exageradas, hiperexpressionistas e marcadas por uma estrutura pictórica cubista. A manipulação das formas faz parte daquilo que os teóricos da arte norte-americanos dos anos 1960 designaram como mechanical cubism. Uma estética que estabelece diálogos entre a pop art e o cubismo. Em Telephone (Figura 1), o artista propõe uma imagem da relação, profundamente ambivalente, entre tecnologia, comunicação e ser humano. O telefone que conecta os dois personagens da pintura ao mesmo tempo os distancia. De costas um para o outro, homem e mulher substituem seus vínculos simbióticos por mediações tecnológicas. A mesma tecnologia que os aproxima também os afasta.

1 Agradecemos a Anouk Papadiamandis a gentileza e autorização de uso das imagens. 
Muitos artistas investigaram as transformações provocadas pela industrialização nas relações entre as pessoas, os objetos e os espaços de ocupação nas casas e nas cidades. Richard Lindner, entretanto, explorou a conexão entre humanos e máquinas. Com construções imagéticas profundamente ambíguas, suas imagens permitem questionar as transformações que as novas tecnologias de informação provocaram sobre o corpo dos seres humanos. Sob um mundo dominado por formas geometrizadas e mecanizadas, o artista constrói a imagem contemporânea da tecnologia não como um instrumento ou objeto técnico à disposição do humano, mas como um dispositivo inscrito em seu próprio corpo.

A Revolução Industrial do século XIX foi uma revolução das tecnologias de trabalho. Máquinas capazes de produzir trabalho a partir do consumo de outras fontes de energia para a produção de efeitos repetitivos em série. Já a revolução das tecnologias de informação do século XX também tem a ver com isolamento causal, mas foi uma revolução não das estruturas de produção de trabalho no mundo físico, mas de produção de informação no mundo simbólico. As tecnologias de informação, diferentemente das máquinas do século XIX, já não são apenas objetos exteriores ao corpo humano que podem ser desligados e guardados, mas dispositivos que integram estruturas sociais de comunicação e potencializam operações, e, por isso, eles já não podem ser simplesmente desligados ou guardados.

Inspirada na obra de Richard Lindner, esta pesquisa pretende discutir a hipótese da autopoiese tecnológica, proposta por Reichel (2011) e Rafael (2013) a partir da teoria dos sistemas sociais de Niklas Luhmann (2007). Trata-se de uma hipótese de alto impacto na observação da sociedade contemporânea, porque, entre outras coisas, ela permite entender a tecnologia não apenas como meio de difusão da comunicação social, tampouco como instrumento de trabalho da ciência aplicada, mas também como um sistema social dotado da capacidade de produzir comunicação segundo sua própria estrutura operativa.

Em quatro ocasiões, Luhmann $(1990,1996 a, 1996 b, 2007)$ discutiu a questão. Pesquisadores contemporâneos têm desenvolvido a problemática luhmanniana em dois sentidos-hipóteses diferentes: 1 . a tecnologia seria um novo meio de difusão da comunicação, sem precedentes na história, que intensifica a função que a invenção da imprensa desempenhou na passagem da sociedade estratificada para a sociedade funcionalmente diferenciada (STOCKINGER, 2005, p. 69); ou 2. a tecnologia seria 
não apenas um novo meio de difusão da comunicação, mas também ela própria estaria produzindo comunicação (SIMIONI, 2010; REICHEL, 2011; RAFAEL, 2013), como é o caso dos sistemas de inteligência artificial e nanotecnologias.

As duas abordagens são interessantes e de alto impacto. Em um nível mais profundo, elas não são contraditórias ou incompatíveis entre si, pois pensar a tecnologia apenas como meio de difusão, como foi a imprensa, não nega totalmente a possibilidade de ela também produzir comunicação, já que a difusão pode ser uma das prestações da tecnologia. Contudo, pensar a tecnologia como possivelmente autopoiética também não nega a prestação de difusão da comunicação para outros sistemas sociais a ela acoplados. Só haverá incompatibilidade entre esses dois desenvolvimentos se a observação da tecnologia como difusão negar a possibilidade de ela também produzir comunicação.

A questão central do estado da arte das pesquisas sobre tecnologia em teoria dos sistemas é se podemos observá-la como um sistema social dotado de autopoiese ou apenas como dispositivos técnicos que desempenham funções por ela não determinadas. Que ela desempenha prestações de difusão, não há dúvida. Que as novas tecnologias de informação possuem um potencial de transformação social equiparável ao da invenção da imprensa no século XV, também não há dúvida. A questão é se a tecnologia pode ser observada como um sistema social dotado de autopoiese, com a consequência, entre outras coisas, de se observar a possibilidade de a função tecnológica ser por ela mesma determinada, com relativa autonomia diante de outros sistemas sociais e inclusive diante das consciências individuais dos seres humanos. Como as máquinas nas pinturas de Lindner, elas não se encontram apenas disponíveis aos corpos humanos, mas fazem parte deles. São dispositivos, como podemos dizer, utilizando a tradição teórica de Maturana e Varela a Luhmann, acoplados estruturalmente aos corpos humanos.

Para o direito, essa hipótese é de alto impacto, pois exigiria pensar a relação entre tecnologia e direito não mais como dispositivo, instrumento, ferramenta, suplemento ou qualquer tipo de prótese funcional, mas também como uma forma de acoplamento estrutural. E no acoplamento, ambos os sistemas produzem interferências recíprocas, o que significa, entre outras coisas, que não só o direito produz alguns condicionamentos seletivos sobre os dispositivos tecnológicos, mas também a tecnologia produz condicionamentos sobre o direito.

Mas, para um sistema ser dotado de autopoiese, ele precisa ter código, programas, função e autodescrição. Este estudo pretende discutir, a partir das pesquisas de Reichel 
(2011) e Rafael (2013), a hipótese de que a tecnologia da sociedade reúne alguns desses elementos estruturantes do conceito de autopoiese de Niklas Luhmann. Não pretendemos discutir a polêmica entre Luhmann e Teubner a respeito das vantagens ou desvantagens de se entender a autopoiese como um processo gradativo, como se um sistema pudesse ser mais ou menos autopoiético. Nosso objetivo é problematizar a possibilidade de se entender a tecnologia no quadro conceitual da teoria dos sistemas sociais, no nível da estrutura formal de um sistema autopoiético, e as relações que essa forma de observação permite estabelecer com o direito.

Para tanto, como metodologia, utiliza-se a observação de segunda ordem da teoria dos sistemas sociais de Niklas Luhmann (2007), de modo a entender as operações tecnológicas como operações que, baseadas na diferença entre código e programas, combinam auto e heterorreferência, bem como desempenham uma função social exclusiva, que nenhum outro sistema social consegue realizar. Por um lado, se a identificação do código, dos programas e da função já é problemática, a dimensão das autodescrições, por outro, parece-nos ainda mais nebulosa e difícil de se captar por meio dos recursos intelectuais de que dispomos no presente. De qualquer modo, a hipótese da autopoiese tecnológica é interessante e pode permitir a abertura de novas pesquisas e novas possibilidades de entendimento dos problemas presentes na relação entre tecnologia, direito, ciência, política e comunicação de massa.

\section{A colocação do problema}

Em 1990, afastando-se de todas as tradições teóricas que pensaram a técnica como ideologia, Luhmann (1990, 1996a, 1996b, 2007) sinalizou a questão da técnica como uma estrutura de simplificação que funciona. Uma forma de isolamento causal diante de um mundo hipercomplexo. Uma forma de reprodução de operações específicas diante de um ambiente complexo, contingente e caótico. Em 1997, em sua grande obra $A$ sociedade da sociedade, Luhmann (2007, p. 412-415) volta a discutir a questão das tecnologias e reafirma a conexão entre técnica e isolamento causal: a tecnologia como uma simplificação que funciona.

Há cinco pressupostos importantes e intimamente conectados na decisão de Luhmann por esse conceito tão abstrato e diferente das tradições teóricas da época, como foram as noções de técnica na fenomenologia hermenêutica de Heidegger (1994, 1995) e Jonas (2006) ou no pensamento crítico de Adorno e Horkheimer (1985), Marcuse 
(1978), Habermas (1994) e Feenberg (1991), ou ainda na tradição do pós-estruturalismo francês de Foucault (1976, p. 183; 2012, p. 404) e Deleuze e Guattari (2010, p. 18). Luhmann não segue essas tradições porque quer pensar a técnica não como racionalização instrumental das esferas tradicionais (WEBER, 1977, p. 457) ou como colonização instrumental do mundo da vida (HABERMAS, 1988, p. 502), mas quer pensá-la na perspectiva da complexidade e do risco. Assim, Luhmann promove pelo menos cinco importantes rupturas com as noções tradicionais de técnica: 1 . rompe com a oposição entre técnica e natureza presente na semântica da téchne grega; 2. rompe com a compreensão humanista da técnica como instrumento, ferramenta ou dispositivo de trabalho para o ser humano ou para a sociedade; e também 3. rompe com a noção ontológica de técnica como ente, porque prefere observá-la como forma de diferença inscrita na comunicação da sociedade; 4. rompe com a noção de técnica como ciência aplicada; e também 5. com a oposição crítica entre técnica e ideologia.

Mas a noção de técnica como simplificação que funciona ficou demasiado abstrata e tão genérica que qualquer sistema social que estrutura complexidade poderia ser chamado de um sistema técnico. É tão genérico que uma teoria científica, um signo linguístico ou a fé religiosa poderiam ser igualmente técnicos, e não haveria, nessa perspectiva, nenhuma diferença significativa entre técnica e o conceito de operação em geral.

Em 1997, em A sociedade da sociedade, Luhmann (2007, p. 234, 412) retomou essa problemática e levantou a questão das profundas transformações decorrentes das novas tecnologias de informação, as quais se situavam no limiar entre difusão e produção de comunicação. Meios de difusão da comunicação são instrumentos, como foi a invenção da imprensa no século XV, que permitem a circulação da comunicação em escala mais ampla e rápida do que os sistemas de interação presencial. A amplificação da comunicação da sociedade, possibilitada pelo meio de difusão que foi a imprensa, desencadeou nada menos do que a passagem da sociedade estratificada para a sociedade funcionalmente diferenciada. Imagina-se então o impacto que as novas tecnologias de informação podem estar desempenhando para a difusão da comunicação, atualmente em escala global e instantânea. Possivelmente estamos vivendo, neste momento, uma nova e profunda transformação social, comparável com a passagem das sociedades estratificadas para as funcionalmente diferenciadas.

Mas não é só isso. Luhmann (2007, p. 90, 234, 319) questionou também a possibilidade de se observarem as operações dessas novas tecnologias de informação não 
apenas como meios de difusão da comunicação de outros sistemas sociais, mas também como genuínos meios de comunicação. A diferença é importante em teorias dos sistemas, porque entender as tecnologias de informação como meios de difusão significa entendê-las apenas como instrumentos de outros sistemas sociais, como o caso dos mass media, enquanto entendê-las como meios de comunicação significa entender que as tecnologias de informação não se limitam a difundir comunicação de outros sistemas, mas que elas mesmas produzem a distinção entre informação, mensagem e entendimento da informação como informação emitida, a partir da sua própria estrutura de operações.

No campo da comunicação jurídica, bases de dados informatizadas permitem a difusão das operações jurídicas em escala global e instantânea. Mas uma coisa é a tecnologia produzir novas e poderosas formas de difusão da comunicação do direito, criando, como observou Bastos (2013, p. 194), um excesso de complexidade que alterou não só a cultura, mas também a estrutura material da sociedade; outra é ela produzir novas formas de comunicação a partir de sua própria estrutura, condicionando, como nas pinturas de Lindner, as possibilidades de sentido do direito que dela se serve para comunicar.

Na época de Luhmann, as nanotecnologias não eram apenas instrumentos técnicos para observar uma realidade que, sem elas, seria impossível observar. Não eram apenas ciência aplicada. Nanotecnologias produziam informações por conta própria. Eram tecnologias que não se limitavam, na época, a instrumentalizar a observação de cientistas ou engenheiros, mas que elas próprias poderiam gerar informações a partir de suas próprias redes operacionais.

Mas produzir informação não significa ainda produzir comunicação. Em teoria dos sistemas, comunicação não é sinônimo de informação. Informação é apenas uma diferença dotada da potencialidade de sentido. Não é ainda comunicação. Comunicação é uma operação mais complexa, porque ela envolve três operações: informação, emissão e entendimento da informação emitida como diferença entre informação e emissão (LUHMANN, 1993, p. 42; 1998, p. 140; 2007, p. 145). Se as tecnologias apenas produzem informação, elas não podem ser consideradas ainda como sistemas de comunicação. Mas se, como começavam a demonstrar os computadores e nanotecnologias da época, sistemas de informação não só produzem informação, mas também as emitem como diferença entre informação e emissão ou anulam a unidade da diferença entre emissão e entendimento(LUHMANN, 2007, p. 239), então, possivelmente, essas tecnologias já estariam no limiar entre sistemas de difusão e sistemas de comunicação. 
Uma terceira reflexão proposta por Luhmann (2007, p. 243) à questão da tecnologia é a da confiança. Na medida em que a sociedade começa a assumir as informações produzidas tecnologicamente como operações de comunicação, a confiança que antes dependia da autoridade e credibilidade das pessoas, instituições ou organizações começa a se deslocar para uma nova forma de confiança, desconectada de pessoas e conectada apenas a sistemas tecnológicos. Uma forma de confiança puramente sistêmica (LUHMANN, 2007, p. 243). A autoridade e a credibilidade dos especialistas, como advogados, médicos, psicólogos ou engenheiros, começam a sofrer profundas transformações. A sociedade desconfia da autoridade dos especialistas e passa a confiar em sistemas tecnológicos.

A quarta questão luhmanniana é o rompimento das relações entre espaço e tempo operadas pelas novas tecnologias de informação(LUHMANN, 2007, p. 344). Para saber das coisas, antigamente as pessoas precisavam se deslocar às escolas, universidades e bibliotecas. As aulas e os estudos tinham não só hora marcada, mas também lugar determinado. As informações possuíam endereços físicos e tinham horário para serem disponibilizadas. As tecnologias de imprensa já produziram uma primeira ruptura com a questão do espaço e tempo quando os jornais, o rádio e a TV puderam ser consumidos em casa ou em qualquer lugar, inclusive fora do horário comercial, à noite ou, no caso do jornal, quando o leitor quisesse. Mas as novas tecnologias de informação baseadas na internet produzem uma nova importante transformação, porque agora sequer é necessário aguardar o tempo da programação ou o lugar da TV, do rádio ou jornal. A informação está, hoje, na palma da nossa mão, em nossos smartphones, em qualquer tempo e lugar. A possibilidade de assistir ao vivo à programação de uma TV do outro lado do mundo e inclusive quando e onde quiser, porque a programação fica disponível em plataformas como o YouTube, rompe com as referências tempo-espaciais que limitavam as tecnologias de difusão das informações até então conhecidas.

As questões levantadas por Luhmann, portanto, são basicamente quatro: 1. saber se um sistema tecnológico produz comunicação como diferença entre informação e emissão da informação; 2. saber se um sistema tecnológico anula a diferença entre emissão da informação e entendimento da informação emitida; 3. analisar as transformações sociais decorrentes do deslocamento da confiança para sistemas tecnológicos; e 4. o rompimento das relações entre espaço e tempo.

Que eles produzem informação no sentido de meios de difusão, não há dúvidas. E isso já constitui um alto impacto para a compreensão da sociedade contemporânea, 
especialmente se comparada com os impactos da invenção da imprensa, que permitiu a difusão da comunicação para muito além dos sistemas de interação presenciais e o desenvolvimento da autopoiese do sistema dos mass media. Mas, se a tecnologia produz informações no sentido de meios de comunicação, que operam 1. distinções entre informação e emissão ou 2. anulam a distinção entre emissão e entendimento, isso é uma questão ainda em aberto. Porque na medida em que um sistema tecnológico produz mais que difusão da comunicação de outros sistemas para tornar-se, ele próprio, um sistema de comunicação, então poderíamos estar diante da emergência de um novo sistema social dotado de autopoiese, tão importante quanto o direito, a política, a ciência, a religião, a arte, a economia e os meios de comunicação de massa.

Niklas Luhmann faleceu em 1998. Ele conheceu a inteligência artificial, o e-mail, a internet e a globalização da comunicação de massa. Mas não existiam ainda as redes sociais de internet, com exceção das redes privadas em empresas e universidades. Mesmo assim, o modo como ele colocou a questão da tecnologia apresenta uma potencialidade de sentido sem precedentes na história. Importantes pensadores como Heidegger $(1994,1995)$ no campo da fenomenologia hermenêutica, Adorno e Horkheimer (1985), Marcuse (1978), Habermas (1994) e Feenberg (1991) no campo do pensamento crítico, como também Foucault (1976, p. 183; 2012, p. 404) e Deleuze e Guattari (2010, p. 18) na linha do pós-estruturalismo francês ou Jonas (2006), Latour (2012), Harman (2011), Markus Gabriel (2018) e Yuk Hui (2016), também pesquisaram a relação entre técnica, linguagem e ser; técnica, ciência e ideologia; e técnica, sistemas de discursividade e regimes de poder. Todas elas foram e são pesquisas relevantes, cujos frutos podemos ver hoje em importantes referências do estudo da tecnologia no mundo contemporâneo. Mas uma outra possibilidade de se entender a tecnologia, aberta por Luhmann em 1990, quando da publicação de $A$ ciência da sociedade, também merece ser lembrada: a técnica pode ter a ver com isolamento causal e não apenas com poder, ideologia ou um existencial protético da humanidade.

Como nas pinturas de Lindner, a mesma tecnologia que conecta as pessoas também as afasta. Os mesmos dispositivos técnicos que permitem criar autonomia também geram dependência. E os mesmos aparelhos tecnológicos que, como extensões do nosso corpo, ajudam a melhorar nossa vida e facilitar a realização de tarefas também nos aprisionam. 


\section{As hipóteses de Reichel e Rafael}

Para um sistema poder ser observado como sistema social autopoiético, ele precisa ser entendido como uma efetuação de operações no tempo, baseadas em suas próprias operações precedentes. Um sistema social dotado de autopoiese não pode ser observado apenas como meio ou instrumento para a efetuação das operações de outros sistemas. Também não são ferramentas de trabalho para seres humanos. Sistemas sociais autopoiéticos efetuam-se a si mesmos a partir de si mesmos. Código, programas, função e autodescrições constituem as quatro dimensões estruturais de um sistema social desse tipo. Se faltar uma delas, não haverá autopoiese.

Gunther Teubner e outros procuraram, nos anos 1990, desenvolver um conceito diferente de autopoiese, menos rigoroso e concebido em termos de graduação. Para Teubner (1997, p. 57), autopoiese não é uma característica que ou existe ou não existe em um sistema, mas que pode ser conquistada aos poucos, de modo gradativo. Um sistema pode desenvolver a capacidade de auto-observação, auto-organização, autorreferência até chegar à autopoiese plena. Como problematizaram Simioni et al. (2016, p. 283), Luhmann respondeu criticamente à proposta do gradualismo autopoiético de Teubner em diversas ocasiões, reafirmando a importância de se entender a autopoiese não como um ideal normativo, mas como uma característica que ou se verifica empiricamente na comunicação ou não se verifica. Em Luhmann, portanto, o entendimento da tecnologia como um possível sistema autopoiético exige uma compreensão não gradativa da autopoiese.

Luhmann (1996b, p. 102; 2007, p. 414) nos ajudou a pensar na função da tecnologia como uma forma de produção de isolamento causal, como simplificação que funciona. Eisso, por si só, já foi uma enorme contribuição para a hipótese que esta pesquisa procura discutir. Definir a função já é um importante caminho para se pensar na estrutura que conecta formas especiais de sentido na comunicação da sociedade. Somente a função, contudo, não é suficiente para um sistema poder ser observado em sua recursividade operativa. Para entendermos as operações tecnológicas como operações dotadas da combinação entre auto e heterorreferência, precisa-se definir o modo como a comunicação tecnológica se diferencia funcionalmente das demais formas de comunicação da sociedade e afirma, assim, sua própria identidade como diferença em relação ao ambiente. Na teoria dos sistemas de Niklas Luhmann, a dimensão da estrutura conceitual que designa essa operação de construção da identidade do sistema como diferença em relação ao ambiente se chama código. 
Código é uma forma de diferença estruturada em apenas dois valores binários autoexcludentes. Enquanto a forma simboliza a unidade da diferença entre identidade e diferença (SPENCER-BROWN, 1979, p. 2), o código também é uma forma, mas uma forma com dois valores lógicos historicamente bem definidos, por meio de um processo social de consolidação e confirmação desses dois valores lógicos. A forma não define, necessariamente, quais valores estarão no lado não marcado da diferença por ela constituída. A forma não define seu próprio unmarkspace (SPENCER-BROWN, 1979, p. 4). O código define tanto o marked quanto o unmarkedspace.

O código é uma forma de sentido historicamente consolidada na comunicação social. É uma forma especial que não deixa seu lado não marcado na contingência de um sentido aberto a várias possibilidades. $\mathrm{O}$ código tem tanto o lado positivo quanto o negativo consolidados e condensados (SPENCER-BROWN, 1979, p. 9) de modo que, ao se fazer referência ao lado positivo, o negativo já se encontra estruturalmente com ele determinado.

Os dois valores do código, portanto, não são arbitrários. São historicamente contingentes, mas não arbitrários. Para observarmos o código da tecnologia - se é que ele existe -, precisamos observar não os tecnólogos, mas a comunicação da tecnologia. A pergunta pelo código da tecnologia exige a observação da história da comunicação referida à tecnologia. Exige a observação do outro lado da forma de distinção. Podemos começar a entender o outro lado da forma perguntando: contra o que se fala em tecnologia?

Seguindo a perspectiva de Luhmann, Reichel (2011, p. 109) propôs entender o código tecnológico como a diferença entre funcionamento e falha - work/fail - e a operatividade - operativeness - como o meio sobre o qual opera o código. Por sua vez, Rafael (2013, p. 332) preferiu entender o código da tecnologia como a diferença entre estado da arte e obsoleto - state-of-the-art/obsolete.

A proposta de Reichel (2011) do código funcionamento/falha para a tecnologia é interessante, porque ela se conecta tanto com as pesquisas de Luhmann sobre a técnica como simplificação que funciona, quanto com os cinco pressupostos sistêmicos observados anteriormente, de uma compreensão da tecnologia como algo da sociedade e não dos sujeitos individuais. Contudo, a distinção entre funcionamento e falha pode estar inserida na semântica científica da tentativa e do erro, e, por essa razão, esse código parece colocar a tecnologia na posição ambígua de um limiar entre o acoplamento com a ciência e apenas um subsistema dela. Pensar a tecnologia como sistema social autopoiético exige pensar a autonomia dela também em relação à ciência. A proposta 
de Reichel (2011) é interessante, mas ela pode colocar a técnica na mesma posição da técnica como ciência aplicada.

Por sua vez, funcionamento/falha é uma proposta interessante do ponto de vista da teoria da evolução, segundo a qual a tecnologia se orientaria pela falha, para buscar o funcionamento. Essa referência basal permite entender a tecnologia com autonomia em relação a outros sistemas sociais e também em relação à humanidade. Além disso, esse código parece conectar bem a dependência e a onipresença da tecnologia em nossa vida de hoje, não só das tecnologias das máquinas e ferramentas, mas também das tecnologias da informação. A distinção traçada pela diferença entre funcionamento e falha, sem definição do que funciona e do que falha, permite entender que a própria tecnologia controla o funcionamento de si mesma. A própria tecnologia define o que funciona e o que falha para ela. Como os dispositivos maquínicos de Lindner, não se trata de funcionamento e falha para o humano, mas de operações técnicas orientadas à própria rede tecnológica disponível: a tecnologia controlando a própria tecnologia.

A operatividade como medium também é interessante na proposta de Reichel (2011, p. 109), porque, na tradição da distinção de Fritz Heider (1970, p. 29) entre meio e forma, a operatividade seria exatamente um meio definido pela própria forma tecnológica. É uma estratégia inteligente de observação da autorreferência das operações tecnológicas. Funcionamento e falha em um meio de operatividade que é definido pela própria diferença entre funcionamento e falha.

As consequências que Reichel (2011) conclui também são de alto impacto para uma compreensão sistêmica da tecnologia. Ele observa a tecnologia como um sistema diferente dos sistemas sociais, porque suas operações estariam localizadas, dentro do desenho teórico luhmanniano, entre sociedade e indivíduos (REICHEL, 2011, p. 110), e ela realiza o acoplamento entre indivíduo, sociedade e ambiente natural. Assim, como na noção de técnica em Heidegger (1994, p. 37), a tecnologia se situa no limiar entre sociedade, indivíduos e ambiente natural, produzindo ressonâncias sobre essas três dimensões da cognição e do agir humano.

Já Rafael (2013, p. 332) propõe outro código para entender a tecnologia como sistema social: estado da arte/obsoleto - state-of-the-art/obsolete. Do mesmo modo que Reichel, a tecnologia para Rafael (2013, p. 319) também se guia pelo lado negativo do código, mas, segundo ele, o obsoleto é o valor do código que reflexiona a tecnologia para a constante inovação e capacidade inventiva. 
Se o código proposto por Reichel pode estar fortemente conectado à semântica da ciência, o de Rafael pode estar na semântica da economia. Isso ocorre porque a diferença entre estado da arte e obsolescência remete a uma questão de utilidade econômica da tecnologia, atualmente inflacionada pelos discursos/semânticas da tecnologia como inovação - e da inovação como tecnologia. Também Rafael (2013, p. 322) possui as vantagens do distanciamento das concepções humanistas da tecnologia, que a enxergam como instrumentos ou próteses humanas. Mas, diferentemente de Reichel, Rafael (2013, p. 341) a entende como um fenômeno do ambiente da sociedade. Reichel observa a tecnologia como um ambiente tanto dos indivíduos quanto da sociedade. É um sistema diferente dos sistemas sociais, porque suas operações estariam localizadas entre sociedade e indivíduos (REICHEL, 2011, p. 110). Rafael, no entanto, entende-a como um fenômeno do ambiente da sociedade.

Segundo nossa leitura, a proposta de Rafael não permite entender a autorreferência e autonomia das operações tecnológicas em relação à economia. Isso não significa que Reichel está certo, pois não se deve descartar a hipótese de que a economia tenha se apropriado da técnica, que nessa hipótese não seria mais uma ciência aplicada, mas uma economia da inovação. Mas, para a hipótese da autopoiese tecnológica, a proposta construtivista de Reichel parece seguir um caminho potencialmente promissor.

\section{Energia, tecnologia e autonomia}

A divergência sobre o código exige darmos um passo atrás sobre os pressupostos do código. Reichel observou a operatividade como o meio sobre o qual a tecnologia funciona ou falha. Rafael não fez referências ao meio da forma/código. Mas em nenhum deles há referência à energia que faz a tecnologia funcionar.

Em pesquisa sobre a relação entre energia e tecnologia na forma da comunicação jurídica, Simioni (2010, p. 28) sugeriu, sob a perspectiva ecológica da relação entre tecnologia e problemas ambientais, a diferença entre tecnologia e energia como forma de distinção entre meio e forma. A energia é o meio sobre o qual se desenvolvem as formas tecnológicas (SIMIONI, 2010, p. 62). A energia, assim, não apenas condiciona as possibilidades dos novos desenvolvimentos tecnológicos, mas também as tecnologias permitem a produção de novos meios de produção de energia. Essa relação entre 
meio e forma - energia e tecnologia - permite colocar a tecnologia sob uma relação de autorreferência, porque ela abre a possibilidade de se observar a tecnologia não como instrumento de outros sistemas sociais, mas como uma rede de operações por ela mesma determinada.

Operando com base em energia, as tecnologias tornam-se autônomas dos demais sistemas sociais. Para seu funcionamento, já não importa mais se a tecnologia é lícita ou ilícita, se gera poder ou submissão ou se suas operações correspondem à verdade da ciência. Dependendo apenas de energia para seu funcionamento, a tecnologia se desprende das demais estruturas sociais e pode ser observada em sua recursividade operativa.

Operações tecnológicas da sociedade não dependem diretamente da estabilização de expectativas do direito, da verdade da ciência, do poder político ou de pagamentos da economia. A tecnologia funciona com autonomia do ambiente societal. Mas ela depende do seu outro lado, que é a energia. Se faltar energia, a tecnologia não funcionará. Um automóvel furtado funciona exatamente igual a um devidamente adquirido no comércio, como também um computador usado para praticar crimes, para produzir influência política ou para propagar a fé religiosa funciona do mesmo modo, porque eles dependem apenas do aprovisionamento energético para o seu funcionamento.

A conexão entre energia e tecnologia pode ser observada desde os arquétipos mitológicos da ars romana ou da téchne grega. Na mitologia grega, a imagem simbólica do presente de Prometeu aos homens que, para ajudá-los a sobreviver diante dos dons dos demais animais, furtou o fogo dos céus para dar a eles é ilustrativa dessa fundação mitológica da tecnologia: o domínio do fogo como técnica de sobrevivência diante de um ambiente hostil à vida, cuja autonomia é garantida exatamente pela combinação entre o domínio da técnica e o do combustível-energia adequado.

Com Heidegger (1994, p. 16) podemos entender a revolução tecnológica das máquinas do século XIX como mais uma profunda revolução tecnológica da história. As máquinas da Revolução Industrial podem ser observadas como uma enorme e complexa estrutura de produção baseada na autonomia do trabalho em relação às condições ambientais. A força de trabalho da máquina a vapor substituiu a força de trabalho da mão humana ou da tração animal. O homem tornou-se um operador da máquina, e a máquina, um operador do homem e da sociedade, além de uma estrutura econômica de alto impacto na vida do mundo ocidental. 
Nesse nível de abstração do código, as máquinas a vapor da Revolução Industrial são equivalentes funcionais da máquina de impressão dos jornais e panfletos da invenção da imprensa. Ambos são tecnologias cujo funcionamento é autônomo em relação às condições naturais. Não se trata apenas de mais rapidez ou precisão na realização dos respectivos trabalhos, mas sobretudo de mais autonomia do trabalho em relação às condições ambientais. E isso só é possível porque há energia, tecnologicamente aproveitável, pela própria estrutura tecnológica.

A Revolução Industrial é um marco importante para a tecnologia, não apenas porque foi ali que as máquinas iniciaram o processo irreversível de substituição do trabalho humano e animal, mas sobretudo porque iniciaram o processo, igualmente irreversível, de geração de energia. As tecnologias da época, sejam as grandes máquinas a vapor, sejam os pequenos dispositivos mecânicos de aproveitamento da força humana e animal, não operam mais produzindo apenas trabalho para a reprodutibilidade técnica de produtos e bens de consumo, mas também começam a produzir trabalho para a geração de mais energia para elas mesmas.

Autorreferência: uma coisa é aproveitar a energia disponível no mundo para fazer funcionar a tecnologia a ela adequada ou usar tecnologia adequada para aproveitar a energia disponível. Outra coisa, bem diferente, é quando a tecnologia começa a ser utilizada para produzir mais energia, inclusive a energia necessária para o funcionamento das próprias tecnologias de geração de energia. Nesse nível, já se pode observar a autorreferência: tecnologias para o aprovisionamento energético da própria tecnologia.

Todavia, se isso pode ser observado em relação às máquinas, também pode ser observado em relação à nova revolução tecnológica, que é a das tecnologias da informação? Seguindo a hipótese da diferença autoconstitutiva entre energia e tecnologia, é interessante observar que todo o funcionamento das tecnologias de informação está baseado em uma complexa estrutura, igualmente tecnológica, de produção, organização e distribuição de energia elétrica. Do mesmo modo que há um ser humano riscando pedras para acender o fogo na Antiguidade, também hoje há humanos teclando botões diante da tela do computador. Mas não é o humano que define o funcionamento das operações tecnológicas. E também não é exclusivamente a energia. É justamente a correlação entre energia e tecnologia: energia que faz a tecnologia funcionar e tecnologia que a produz-aproveita para garantir a continuidade do seu próprio funcionamento. 
O paradoxo autoconstitutivo pode ser observado na seguinte pergunta: a diferença entre energia e tecnologia é uma diferença energética ou tecnológica? E assim podemos entender o paradoxo sobre o qual a comunicação tecnológica se desenvolve na sociedade, que faz circular a diferença entre tecnologia e energia como uma tensão histórica entre potência de trabalho e eficiência energética que esconde justamente a dependência energética da tecnologia e, ao mesmo tempo, a dependência tecnológica do aprovisionamento energético. Se essa hipótese for correta, então isso explica por que as maiores revoluções tecnológicas da história também foram revoluções nas técnicas de aprovisionamento de energia e vice-versa. Grandes saltos tecnológicos pressupõem saltos nas tecnologias de aprovisionamento de energia.

\section{Função e prestações tecnológicas}

Em teoria dos sistemas, é importante distinguir função, prestações e reflexão. Função é aquilo que só o sistema, de modo exclusivo, desempenha para a sociedade. Prestações são contribuições que o sistema também desempenha para a sociedade, mas não de modo exclusivo e sim como equivalentes funcionais, pois se poderiam realizar as mesmas prestações por outros meios, por outros sistemas. Reflexão é a relação que o sistema estabelece consigo mesmo. É o modo como o sistema realiza algo para ele mesmo.

A função da tecnologia só pode ser pensada, portanto, nesse nível exigente de intelecção daquilo que somente a tecnologia e nenhum outro sistema, estrutura ou operação da sociedade pode fazer. Essa questão afasta, portanto, as noções tradicionais da tecnologia como instrumento de trabalho, como ciência aplicada ou como ideologia. Ela tem mais a ver com conversão de energia, mas isso implicaria assumir que nosso corpo humano também seria um dispositivo técnico, um aparelho tecnológico, e talvez isso não seja um caminho interessante. Seguindo uma sugestão do próprio Luhmann (1996b, p. 102; 2007, p. 414), a função da tecnologia tem a ver com isolamento causal.

O funcionamento da técnica torna possível o acoplamento entre elementos heterogêneos (Luhmann, 2007, p. 416). Ele opera conversões. Converte sinais do mundo físico em informação ou comunicação. E faz isso de modo repetitivo, com altos índices de precisão. Isolando a causalidade, a técnica consegue combinar generalização com 
especificação, aplicação repetível em situações muito diferentes (Luhmann, 2007, p. 417). A tecnologia torna possível a reprodutibilidade de operações sobre o mundo com altos graus de precisão.

Em um mundo em que tudo acontece simultaneamente, a técnica permite isolare controlar o âmbito das seleções do atuar, do decidir entre alternativas e do comunicar. Simultaneidade é caos. Tornar-se autônomo desse caos é a função da técnica. Descolar-se do caos. Desprender-se do caos da simultaneidade por meio da seleção entre o que pode e o que não pode ser realizado pela estrutura tecnológica de cada época.

Desde o domínio da técnica do fogo, passando pelas técnicas agrícolas da Antiguidade, até a técnica das máquinas e as atuais tecnologias de informação, pode ser observada essa profunda relação entre técnica e isolamento causal. O que ela faz é garantir a autonomia do seu próprio funcionamento diante das condições do ambiente, garantir o isolamento das condições ambientais hostis ao seu próprio funcionamento.

Sem a enorme e complexa rede de dispositivos e aparelhos tecnológicos de hoje, a vida humana na Terra, tal como a conhecemos, não seria possível. Se faltar eletricidade, grande parte da estrutura técnica da sociedade sofrerá paralisação: hospitais, escolas, trabalho, comunicação. O nível de dependência tecnológica/energética para a sobrevivência da forma de sociedade atual é alto, porque as condições ambientais do planeta, sem o isolamento causal garantido pelas tecnologias, são hostis a esses níveis de vida. Frio, fome, sede, locomoção, comunicação, tudo depende de tecnologias/energia.

A função de isolamento causal da tecnologia abre uma via interessante também para o entendimento das novas tecnologias de informação. Redes sociais de internet se vendem sob a promessa de conectar as pessoas, mas talvez o que elas fazem seja exatamente isolar as pessoas para conectar apenas seus avatares, apenas suas personas no sentido das máscaras do teatro romano. A questão não é se as tecnologias são boas ou ruins, curadoras ou perversas. Heidegger já respondeu essa questão demonstrando a ambivalência da técnica, que tanto cura quanto mata. Tanto constrói quanto destrói. Os efeitos da técnica, segundo Heidegger (1994, p. 28), são os perigos dos perigos, porque sobre eles não temos controle. Ela funciona com independência também em relação a nós mesmos e aos seus criadores. 
- FIGURA 2 - RICHARD LINDNER, MOON OVER ALABAMA (1963). ÓLEO SOBRE TELA. 204 X 127,7 CM. MUSEO NACIONAL THYSSEN-BORNEMISZA, MADRID

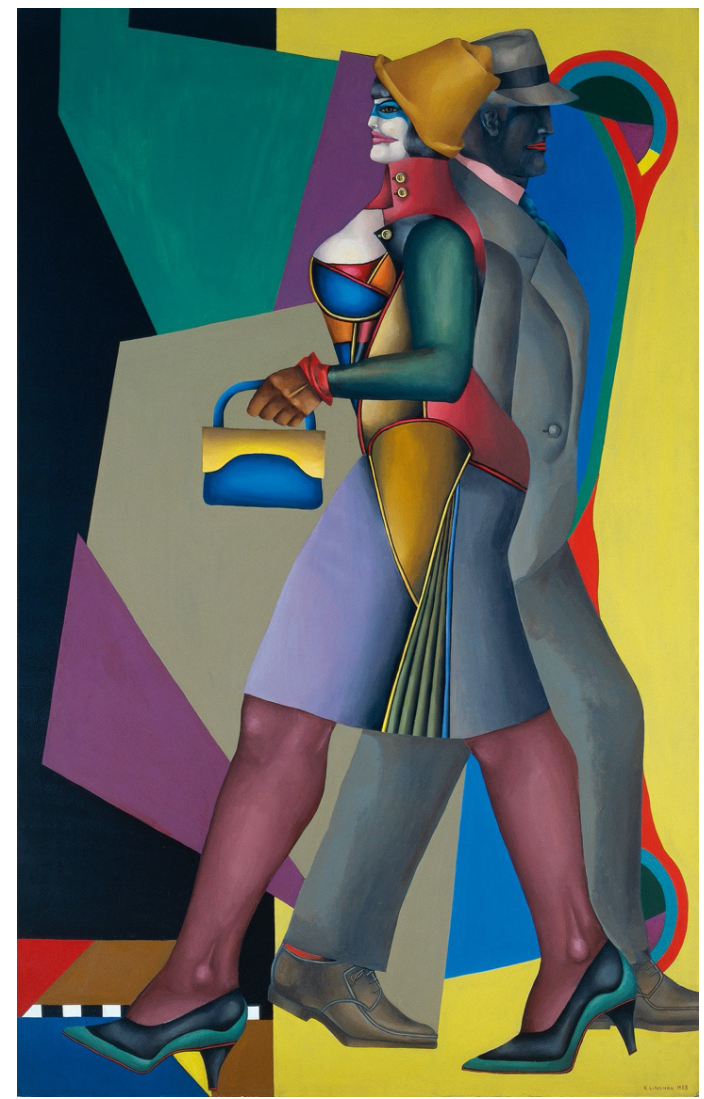

FONTE: REPRODUÇÃO COM AUTORIZAÇĀO DE ANOUK PAPADIAMANDIS, TITULAR DOS DIREITOS DE IMAGEM.

Em Moon over Alabama, Lindner problematiza essa relação ambivalente entre a conexão e o afastamento. Com gestos exageradamente padronizados como os produtos da Revolução Industrial, um homem e uma mulher mecanizados, unidos por um mesmo princípio geométrico, caminham juntos, mas em sentidos opostos. Como objetos produzidos em série pela industrialização, eles estão juntos, mas ao mesmo tempo reciprocamente ignorados um pelo outro. Em um ambiente geometrizado como uma fábrica, a "lua sobre Alabama”, escondida atrás de uma pesada estrutura de formações geométricas, possui um reflexo no chão, como se a técnica não apenas a reproduzisse aqui na Terra, mas também a transformasse em uma forma de saber igualmente técnica. A lua sempre misteriosa e cheia de significados mitológicos encontra, na técnica, 
sua forma simplificada de sentido e de existência. Como pôsteres do mundo da publicidade e propaganda, Lindner conecta humanos e máquinas de modo surrealista, porque é exatamente isso que a técnica faz: conectar o real e o surreal.

Seguindo a esteira de Luhmann, torna-se possível entender a tecnologia não apenas sob uma visão antropocêntrica, que afirma: em um ambiente hostilà vida humana, a técnica desempenha a função especial de garantir a autonomia da vida em relação às condições hostis da natureza; mas também sob uma visão, como podemos dizer, sociocêntrica: a tecnologia também isola as operações dos (demais) sistemas sociais em relação às condições ambientais. Eesse pode ser o caminho para identificar os possíveis acoplamentos estruturais que podem existir entre tecnologia e sistemas sociais como o direito, a política, a economia e a ciência.

\section{Relações entre tecnologia e direito}

Em teoria dos sistemas, as relações entre direito e tecnologia, seguindo a perspectiva da autopoiese, podem ser observadas sob a forma/conceito de acoplamento (MATURANA; VARELA, 2001). Acoplamentos são conexões que ligam zonas de sensibilidade específicas entre sistemas autopoiéticos. Os acoplamentos podem ser operacionais, que são aqueles mais efêmeros, ocorrem em algumas operações e logo se desfazem, e podem ser estruturais, que são os que possuem uma certa duração no tempo.

Que o direito sempre recorreu à técnica para realizar sua força, não é novidade. A tecnologia militar, o gládio da potestas do soberano e as técnicas modernas de vigilância e controle dos corpos carregam consigo essa marca histórica da técnica, do dispositivo e da instrumentalidade do fazer. Mas o isolamento causal para garantir a realização da força do direito não depende apenas dos aparelhos e dispositivos de coerção do poder administrativo de cada época. A espada, a forca, os instrumentos de tortura e a prisão são técnicas de realização do direito, mas que dependiam da legitimidade do poder soberano. $\mathrm{O}$ funcionamento da tecnologia contemporânea, no entanto, não depende de nenhuma legitimidade, porque ele só depende de aprovisionamento energético.

Mas as tecnologias de informação abriram o funcionamento da técnica também em outros ambientes da sociedade. Para o direito, as tecnologias de informação também se conectam com a prestação de transformar eventos do ambiente em informação. Coleta de dados, formação de big data e organização e estruturação de metadados sobre os comportamentos individuais das pessoas e das organizações são algumas prestações das 
tecnologias de informação para o direito. O controle operado pelas tecnologias não é mais apenas um controle de corpos e populações por meio de dispositivos disciplinares, como identificou Foucault (1976, p. 183; 2012, p. 404), mas também, hoje, de vigilância e controle de informações de modo onipresente no tempo e no espaço. Se no tempo de Foucault os dispositivos disciplinares eram os presídios, os hospitais psiquiátricos, as escolas, as fábricas e os quartéis, hoje eles estão em todos os lugares e operando em todos os tempos, inclusive em nossas casas, em nossos celulares, em nós mesmos (HAN, 2017, p. 25).

No campo do direito, a tecnologia produz importantes repercussões sobre os conceitos jurídicos de privacidade, intimidade, personalidade, liberdade, igualdade, autonomia da vontade, contratos, trabalho e fiscalização administrativa. Transforma muitas noções jurídicas até então inquestionadas. No fundo dessas sensibilidades da comunicação jurídica à tecnologia, está a problemática da força administrativa do direito. Esse parece ser o ponto em que tecnologia e direito se conectam. O direito observa a tecnologia como um instrumento da sua observação/efetivação no mundo físico, concreto. Por isso, qualquer mudança na tecnologia produz enormes repercussões na estrutura de realização prática do direito.

Mas, como todo acoplamento estrutural, não se trata de um canal de comunicação entre direito e tecnologia, e sim de uma forma de produção de interferências recíprocas. Uma nova tecnologia de realização do direito no mundo concreto não é tematizada na comunicação jurídica como um novo dispositivo de efetivação do poder administrativo do Estado, mas como uma questão de privacidade, intimidade, vigilância, liberdade, legalidade e competência. Do mesmo modo, do lado da tecnologia, realizar o trabalho jurídico não aparece na comunicação tecnológica no sentido de violações à privacidade, intimidade, liberdade de expressão e competência, mas como problemas técnicos de programação adequada das operações. Problemas de funcionamento/falha, como sugeriu Reichel (2011, p. 109).

Entre direito e tecnologia, pode existir um acoplamento ligado à estrutura técnica de implementação da força coativa do direito e de transformação das informações do ambiente em metadados juridicamente estruturados. Na ausência de um nome adequado, podemos chamar esse acoplamento de aparelho administrativo. E se isso puder ser empiricamente verificado para o direito, também devem existir relações de acoplamento entre tecnologia e economia, política, ciência e arte, que futuras pesquisas poderão observar.

É importante perceber que as tecnologias aplicadas ao direito não são apenas instrumentos à disposição dos juristas para acelerar suas tarefas cotidianas. Os diversos sis- 
- RAFAEL SIMIONI

temas de inteligência artificial não são apenas dispositivos, são sistemas de positividade, regimes de verdade, são formas de comunicação que selecionam algumas possibilidades de conexão e negam outras, que seriam igualmente possíveis. Elas restringem o pluralismo, a diversidade de ideias, as novas abordagens, as experimentações da inteligência, e, falando em inteligência, sufocam qualquer possibilidade de poesia, criação, inovação e surpresa. As tecnologias são “a inovação”, diante da qual tudo o que se segue é apenas repetição seriada e causalmente controlada. Como nas pinturas de Lindner, as tecnologias aplicadas ao direito não são apenas instrumentos, próteses ou suplementos técnicos que operam externamente ao direito. Elas alteram o modo como nos relacionamos com o direito e interferem até mesmo no nível da episteme da cultura jurídica da qual fazemos parte.

\section{Considerações finais}

- FIGURA 3 - RICHARD LINDNER, BOY WITH MACHINE (1954). ÓLEO SOBRE TELA

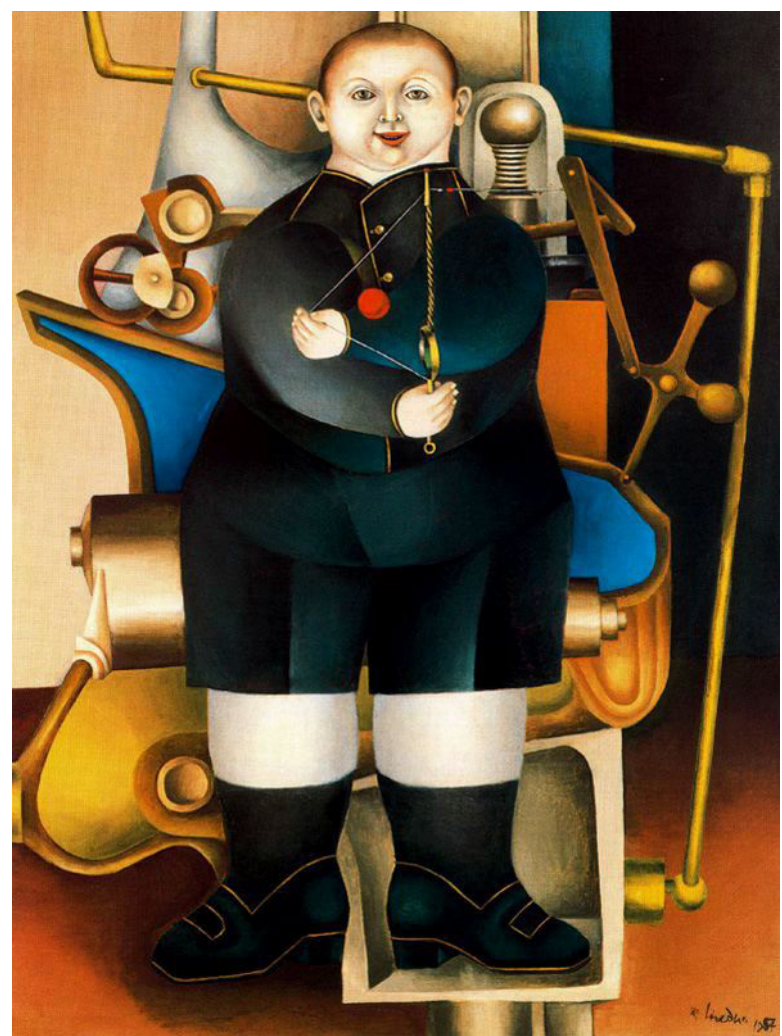


Deleuze e Guattari (2010, p. 19) utilizaram essa pintura de Richard Lindner para ilustrar a desconexão da criança em relação aos vínculos da família e sua reconexão aos vínculos da máquina. O menino obeso brinca com um dispositivo técnico que se conecta a uma máquina maior, como se ela fosse a continuidade do seu próprio corpo. Em Lindner, a técnica não é apenas prótese do corpo humano. Ela é uma forma de extensão da própria existência e, ao mesmo tempo, um dispositivo ambivalente de isolamento e controle. A mesma criança que brinca com o aparelho, como se o controlasse, encontra-se, ao mesmo tempo, aprisionada dentro da própria estrutura técnica da máquina.

Essa mesma ambiguidade da tecnologia também pode ser observada no direito. A mesma tecnologia de informação que promete maior rapidez e precisão na seleção das questões processuais para organização da jurisdição também pode limitar e controlar as possibilidades de novas abordagens jurídicas. A mesma tecnologia que pretende auxiliar as decisões jurídicas em ações repetitivas também controla o que pode e o que não pode ser considerado repetição. A relação entre tecnologia e direito precisa de novos desenvolvimentos no campo da teoria jurídica. Precisamos entender e discutir essa relação, que parece escapar das problemáticas quando tematizada na comunicação jurídica.

A regulação da tecnologia exige uma compreensão diferente do direito. A tecnologia funciona independentemente das condições legais. Sua função é exatamente isolar a seleção das interferências ambientais, inclusive das interferências do direito. A teoria dos sistemas é uma possibilidade diferente de pensar a relação entre tecnologia e direito. Ela aponta para a possibilidade de se entender a técnica como um sistema social dotado de autopoiese, e, se esse for o caso, então as relações dela com o direito só podem ser pensadas em termos de acoplamento estrutural.

Hans Jonas (2006) foi um dos grandes pensadores pós-heideggerianos que se dedicaram ao estudo da relação entre técnica e humanidade. Como na arte de Lindner, Jonas também apontou para o caráter perigosamente ambivalente da técnica, consistente, entre outras coisas, em selecionar uma forma de vida, negando todas as demais, que seriam igualmente possíveis, válidas e legítimas. A tecnologia pode ter sérias dificuldades em lidar com o pluralismo, o multiculturalismo ou com a transdisciplinaridade, pois seu funcionamento está baseado exatamente na reprodutibilidade técnica, no isolamento causal, na autonomização da verdade em relação ao mundo.

Mas para se falar em autopoiese, seguindo o conceito rigoroso de Luhmann, um sistema deve possuir código, programas, função e autodescrição. Salvo se considerarmos os manuais de instruções das tecnologias, não há ainda uma autodescrição tecno- 
lógica consistente em simbolizar a unidade da tecnologia na sociedade. Não há indícios fortes e consistentes para confirmar a hipótese de uma genuína autopoiese tecnológica da sociedade, mas não há sinais de que isso seja impossível de acontecer se o isolamento causal continuar a ser, em uma sociedade caótica na qual tudo acontece simultaneamente, cada vez mais um problema para uma forma específica de operação que, baseada apenas em energia, realiza isso.

\section{REFERÊNCIAS}

ADORNO, T.; HORKHEIMER, M. Dialética do esclarecimento: fragmentos filosóficos. Rio de Janeiro: Jorge Zahar, 1985.

BASTOS, M. T. Uma forma cultural para a sociedade tecnológica. Matrizes, ano 7, n. 1, p. 183-195, jan./jun. 2013.

DELEUZE, G.; GUATTARI, F.O anti-Édipo: capitalismo e esquizofrenia. Tradução Luiz B. L. Orlandi. São Paulo: Editora 34, 2010.

FEENBERG, A. Critical theory of technology. Oxford: Oxford University Press, 1991.

FOUCAULT, M. Histoire de la sexualité I: la volonté de savoir. Paris: Gallimard, 1976.

FOUCAULT, M. Il faut défendre la société: cours au Collège de France (1975-1976). Paris: Gallimard, Seuil, 2012.

GABRIEL, M. El ser humano y los limites del transhumanismo. In: ENCUENTROS DE FILOSOFÍA INTERCULTURA CANARIAS, 2018.

HABERMAS, J. Teoría de la acción comunicativa II: racionalidad de la acción y racionalización social. Traducción Manuel Jiménez Redondo. Madrid: Taurus Ediciones, 1988.

HABERMAS, J. Técnica e ciência como “ideologia”. Lisboa: Edições 70, 1994.

HAN, B.-C. Sociedade do cansaço. Tradução Enio Paulo Giachini. Petrópolis: Vozes, 2017.

HARMAN, G. The quadruple object. Alesford: Zero Books, 2011.

HEIDEGGER, M. La pregunta por la técnica. In: HEIDEGGER, M. Conferencias y artículos. Traducción Eustaquio Barjau. Barcelona: Serbal, 1994.p. 9-37.

HEIDEGGER, M. Língua de tradição e língua técnica. Tradução Mário Botas. Lisboa: Veja, 1995.

HEIDER, F. Psicologia das relações interpessoais. Tradução Dante Moreira Leite. São Paulo: Pioneira, USP, 1970.

HUI, Y. The question concerning technology in China: an essay in cosmotechnics. Falmouth: Urbanomic, 2016.

JONAS, H. O princípio responsabilidade: ensaio de uma ética para a civilização tecnológica. Tradução Marijane Lisboa e Luiz Barros Montez. Rio de Janeiro: PUC-Rio, 2006. 
LATOUR, B. Reagregando o social: uma introdução à teoria do ator-rede. Salvador: Edufba; Bauru: Edusc, 2012.

LUHMANN, N. Technology, environment and social risk: a systems perspective. Industrial Crisis Quarterly, v.4, n. 3, p. 223-231, 1990.

LUHMANN, N. A improbabilidade da comunicação. 3. ed. Tradução Anabela Cavalho. Lisboa: Vega, 1993.

LUHMANN, N. La ciencia de la sociedad. Traducción Silvia Pappe, Brunhilde Erker y Luis Felipe Segura, coordinación Javier Torres Nafarrate. Guadalajara: Iteso, Universidad Iberoamericana; Barcelona: Anthropos, 1996a.

LUHMANN, N. Sociologia del rischio. Traducción Giancarlo Corsi. Milano: Bruno Mondadori, 1996b.

LUHMANN, N. Sistemas sociales: lineamientos para una teoría general. Traducción Silvia Pappe y Brunhilde Erker, coordinación Javier Torres Nafarrate. Barcelona: Anthropos; México: Universidad Iberoamericana, 1998.

LUHMANN, N. La sociedad de la sociedad. Traducción Javier Torres Nafarrate. Ciudad de México: Herder, Universidad Iberoamericana, Daad, Cátedra G. A. Humboldt, 2007.

MARCUSE, H. A ideologia da sociedade industrial. Rio de Janeiro: Jorge Zahar, 1978.

MATURANA, H.; VARELA, F. A árvore do conhecimento: as bases biológicas da compreensão humana. Tradução Humberto Mariotti e Lia Diskin. São Paulo: Palas Athena, 2001.

RAFAEL, E. F. Technology as a social system: a systems theoretical conceptualization. Philippine Sociological Review, v. 61, n. 2, p. 319-347, July/Dec. 2013.

REICHEL, A. Technology as system: towards an autopoietic theory of technology. International Journal of Innovation and Sustainable Development, v. 5, n. 2-3, p. 105-118, 2011.

SIMIONI, R. L. Direito, energia e tecnologia: a reconstrução da diferença entre energia e tecnologia na forma da comunicação jurídica. Curitiba: Juruá, 2010.

SIMIONI, R. L. et al. Direito e gradualismo autopoiético: o debate entre Luhmann e Teubner a respeito da autopoiese jurídica como um processo gradativo. Argumenta Journal Law, n. 25, p. 281-300, jan/jun. 2016.

SPENCER-BROWN, G. Laws of form. New York: Dutton, 1979.

STOCKINGER, G. Nova mídia: autopoiese da tecnologia e co-evolução social. Revista Tecnologia e Sociedade, n. 1, p. 59-69, out. 2005.

TEUBNER, G. O direito como sistema autopoiético. Tradução José Engrácia Antunes. Lisboa: Fundação Calouste Gulbenkian, 1997.

WEBER, M. Economía y sociedad: esbozo de sociología comprensiva. 2. ed. Traducción José Medina Echavarría et al. Bogotá: Fondo de Cultura Económica, 1977. v. I. 